Joachim Höpfner

\title{
Seasonal oscillations in length-of-day
}

\author{
Paper presented \\ at the XXI General Assembly \\ European Geophysical Society \\ The Hague, The Netherlands \\ 6-10 May, 1996
}

Scientific Technical Report STR96/03 


\title{
Seasonal oscillations in length-of-day
}

\author{
Joachim Höpfner \\ GeoForschungsZentrum Potsdam, Division 1: Kinematics and Dynamics of the Earth,Telegrafenberg, D-14473 \\ Potsdam, Germany; E-mail: ho@gfz-potsdam.de
}

\begin{abstract}
Variations of annual and semiannual oscillations in rotation parameters have been investigated on the basis of length-of-day (LOD) as well as atmospheric-angular-momemtum (AAM) time series. These oscillations were determined using band-pass filters. In order to show the character of variations of seasonal oscillations, amplitudes, phases and periods were computed by a least-squares adjustment with the method of modified harmonic analysis at quarterly intervals. In addition, the seasonal imbalances in LOD and AAM budgets were determined and analysed in a similar way. These discrepancies were corrected for tidally excited effects. The non-atmospheric oscillations without the annual tide effect $\mathrm{Sa}$ and the semiannual tide effect Ssa have changeable amplitudes between 0.02 and $0.10 \mathrm{~ms}$.
\end{abstract}

Key words: Earth's rotation, LOD (length of day), AAM (atmospheric angular momentum), seasonal oscillations

\section{Introduction}

Changes in the Earth system take place on various space and time scales. They reflect processes and cycles with complicated interactions. Phenomena of global dynamics of the Earth are the motions of the rotational axis in space (precession and nutation motions) and in the terrestrial body (polar motion) as well as the variations of the angular velocity or lengthof-day variations (changes in the Earth's rotation). These variations of the Earth's rotation vector are caused by external forces (gravitational forces of the Sun, Moon and planets) and internal geophysical processes. If the Earth's rotation behaviour is described in the rotating, terrestrial body-fixed reference frame, the recorded effects mainly have geophysical causes. Variations in the polar motion and Earth rotation are caused by processes associated with mass redistributions and coupling torques, i. e., dynamic processes. Therefore the research of the Earth's rotational behaviour and its relation to dynamic processes is important for the progress in knowledge. Here the major objective is to develop a model of dynamics of the Earth as completely as possible.

Since the middle of the seventies, Satellite-Laser-Ranging (SLR) data are used for determining temporal variations of the Earth rotation parameters (ERP). Compared to earlier data, the time series obtained in this way have a higher accuracy and a higher temporal resolution. Complementary to the series of Earth Rotation Parameters there are atmospheric angular momentum (AAM) estimates derived from meteorological data. The annual and semiannual oscillations in polar motion and length-of-day are dominated by atmospheric effects. This has been shown in recent investigations (Höpfner 1995a-d, 1996) which involve ERP data computed by the International Earth Rotation Service (IERS) and AAM data computed by the U. S. National Meteorological Center (NMC) at daily intervals from 1976 to 1987, i. e. Modified Julian Date (MJD) from 42960.0 to 47160.0 . The purpose of this paper is to present the seasonal oscillations in LOD and AAM and discuss their variability with time as well as to show how much non-atmospheric excitations contribute to seasonal oscillations of Earth rotation.

\section{Data sets}

In this study the following series of data have been used:

(a) LOD series

Earth rotation parameters at one-day intervals computed by the GeoForschungsZentrum Potsdam (GFZ) labelled ERP (GFZ) L04 using Satellite-Laser-Ranging data to Lageos starting in June 1983 and updated till Mid-August 1993 (MJD 

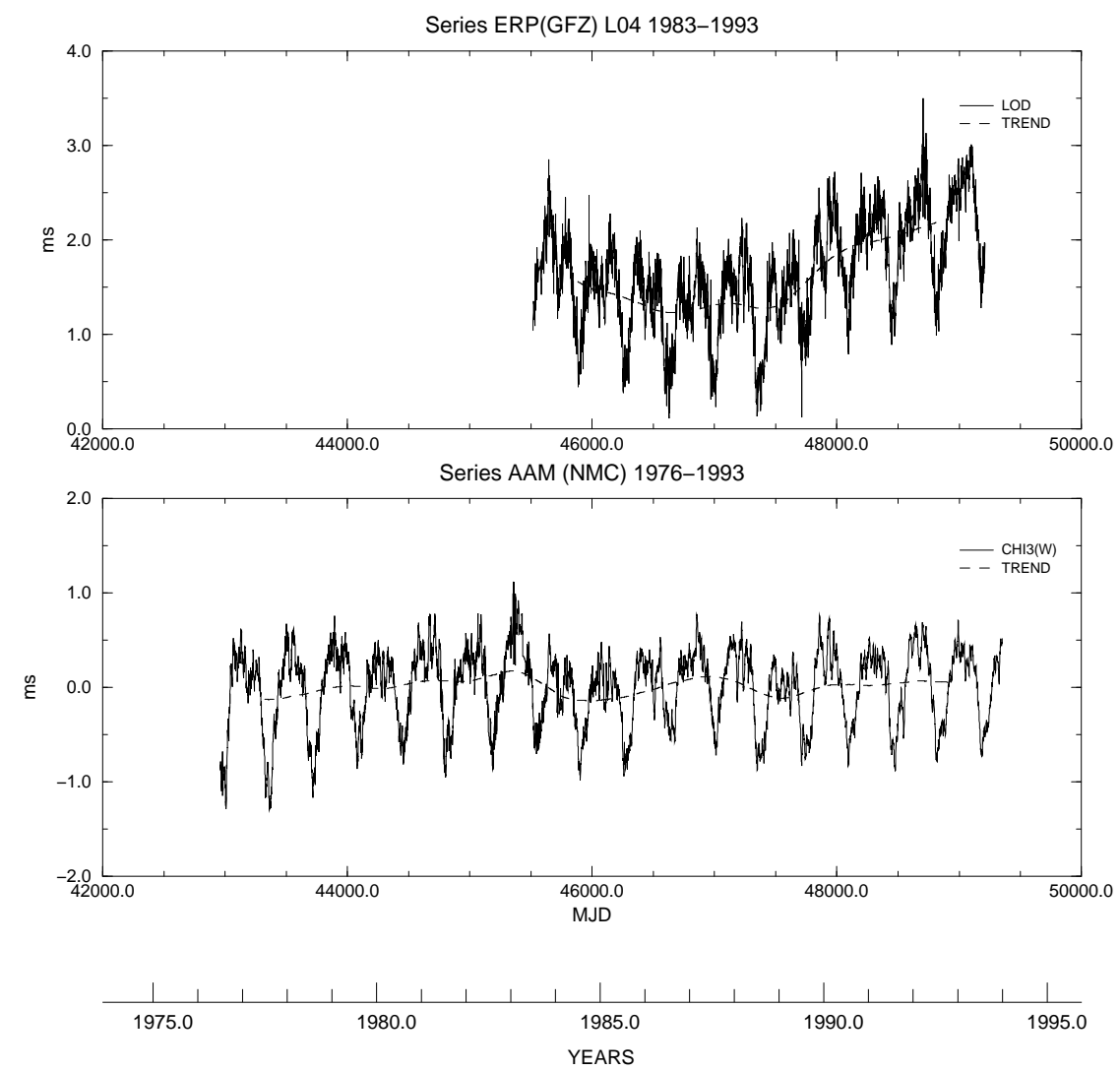

Figure 1. Top: Length-of-day variation as measured by space geodetic techniques computed by the GFZ defined to be LOD. Bottom: Length-of-day variation as inferred by atmospheric-angular-momentum computed by the NMC defined to be LOD atm. Both time series together with their trends

from 45516.0 to 49209.0); the estimated ERP are polar motion x, y and LOD (Montag et al. 1993, 1994). From the LOD, tidal oscillations were removed with periods up to 35 days (McCarthy 1992). Therefore the tidal effects Sa and Ssa are still contributing to the seasonal oscillations of LOD.

(b) $\chi_{3}(\mathrm{~W})$ series

Atmospheric-angular-momentum functions at one-day intervals computed by the U. S. National Meteorological Center (NMC) labelled AAM (NMC) using atmospheric wind and pressure data starting in July 1976 (MJD 42960.0) and updated till December 1993 (MJD 49352.0); the values related to ERP are the equatorial components $\chi_{1}, \chi_{2}$ and the axial component $\chi_{3}$ for Wind (W) and Pressure (P) without and with Inverted Barometer (IB), provided by IERS.

LOD is the excess of the duration of the day to 86400 seconds. At seasonal and higher frequencies variations in LOD are mainly caused by exchange of axial angular momentum between the atmosphere and the solid Earth. The main contributions to $\chi_{3}$ are global zonal winds in the troposphere and the stratosphere. Since changes in $\chi_{3}$ are accompanied by equal but opposite changes in the Earth's angular momentum, we have:

$\mathrm{LOD}_{\mathrm{atm}}=-\chi_{3}(\mathrm{~W})$,

where $\mathrm{LOD}_{\mathrm{atm}}$ are the atmospheric variations of LOD, i. e., LOD inferred from AAM.

There are discrepancies between LOD and $\mathrm{LOD}_{\mathrm{atm}}$. These are given by

$\mathrm{LOD}_{\text {non-atm }}=\mathrm{LOD}-\mathrm{LOD}_{\mathrm{atm}}$,

where $\mathrm{LOD}_{\text {non-atm }}$ are the so-called non-atmospheric variations of LOD.

The data sets of LOD and LOD ${ }_{\text {atm }}$ are shown in Figure 1. The variations in both curves have three major components: trend, annual and semiannual oscillations which change with time. For studying the behaviour of variable components it is suitable to separate them by using filters. 


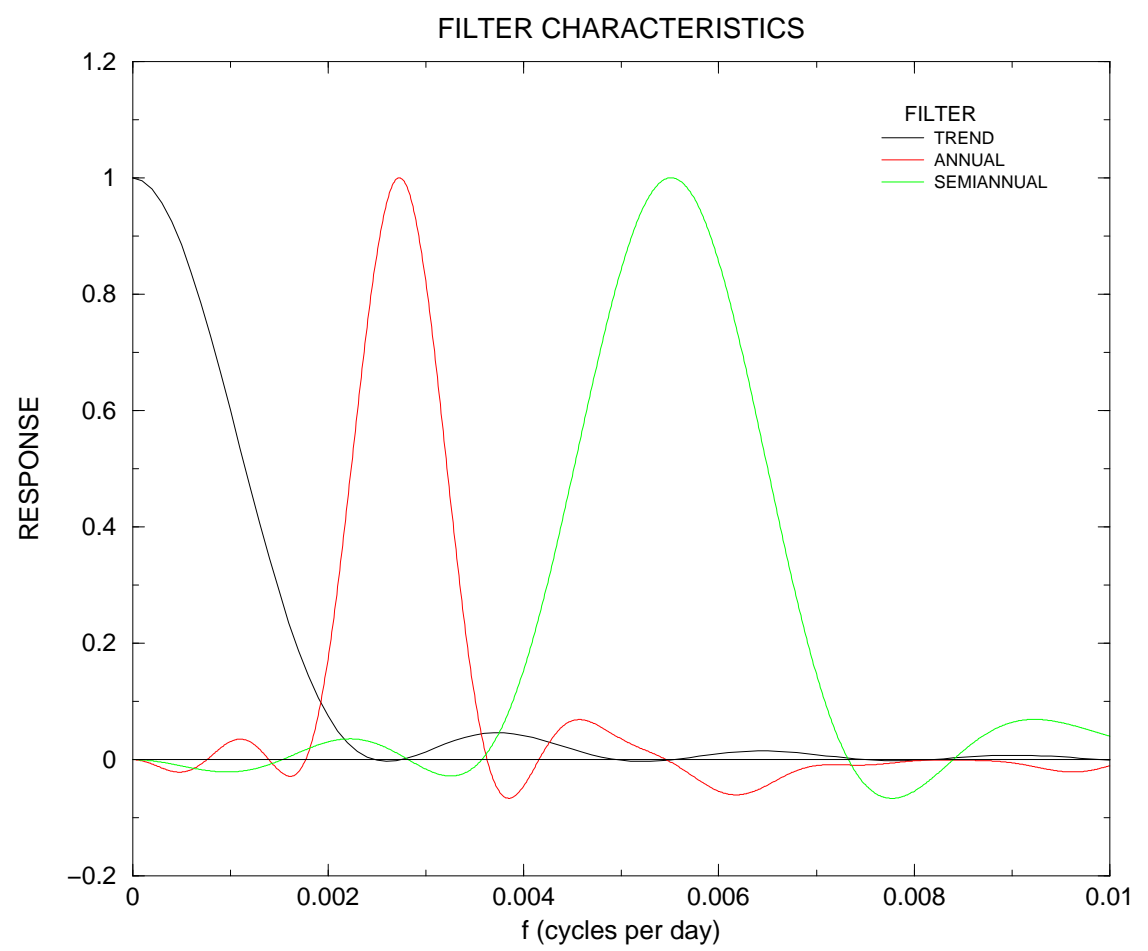

Figure 2. Filter characteristics of the filters applied for separating the trend as well as the annual and semiannual oscillations from the original time series

\section{Filters, their characteristics and filter results}

Linear transversal filters with the form of a moving weighted average have be designed for separating the major components:

(a) Low-pass filter

The filter is a 731-term window with weights from 1 to 10 and the sum of the weights reaching 4024. The smoothing procedure averages out variations with periods of less than 475 days nearly completely. It yields the trend component, where the first and last 365 values of the original time series cannot be processed in this manner, i. e., the series of the trend are truncated at the beginning and at the end.

(b) Band-pass filters

The filters for separating the annual and semiannual oscillations are a 1589-term window and a 787-term window, respectively. They have a cosine shape modified over four periods as weight function. By applying the band-pass filters the filtered series are truncated by 794 and 393 values, respectively, at both edges of the analysis interval. Both filters yield results for the suitable central frequency in a narrow frequency range.

Figure 2 shows the characteristics of the filters used here. As can be seen, the different components are well-separated from each other by using the designed filters.

The trend of the length-of-day variation is characterized by slow variations driven by the dynamical influence of the Earth's liquid core and climatic variations in the atmosphere (see e. g. Dickey 1990). The trends in LOD and LOD atm obtained by low-pass filtering the original data are shown in Figure 1.

The annual and semiannual oscillations of LOD and LOD

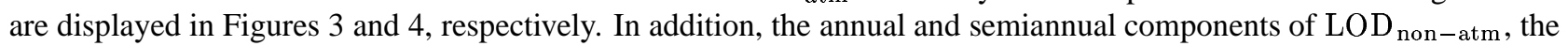
annual and semiannual effects Sa and Ssa induced by the tides of the solid Earth and oceans computed by adopting IERS

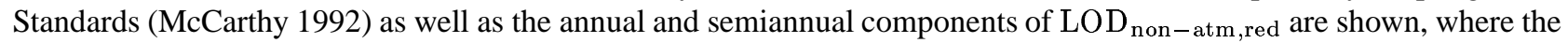
subscript non-atm,red means that the seasonal non-atmospheric components were reduced, i. e. corrected for the tidal effects $\mathrm{Sa}$ and Ssa, respectively. 
Publication: Scientific Technical Report

No.: STR96/03

Author: J. Höpfner
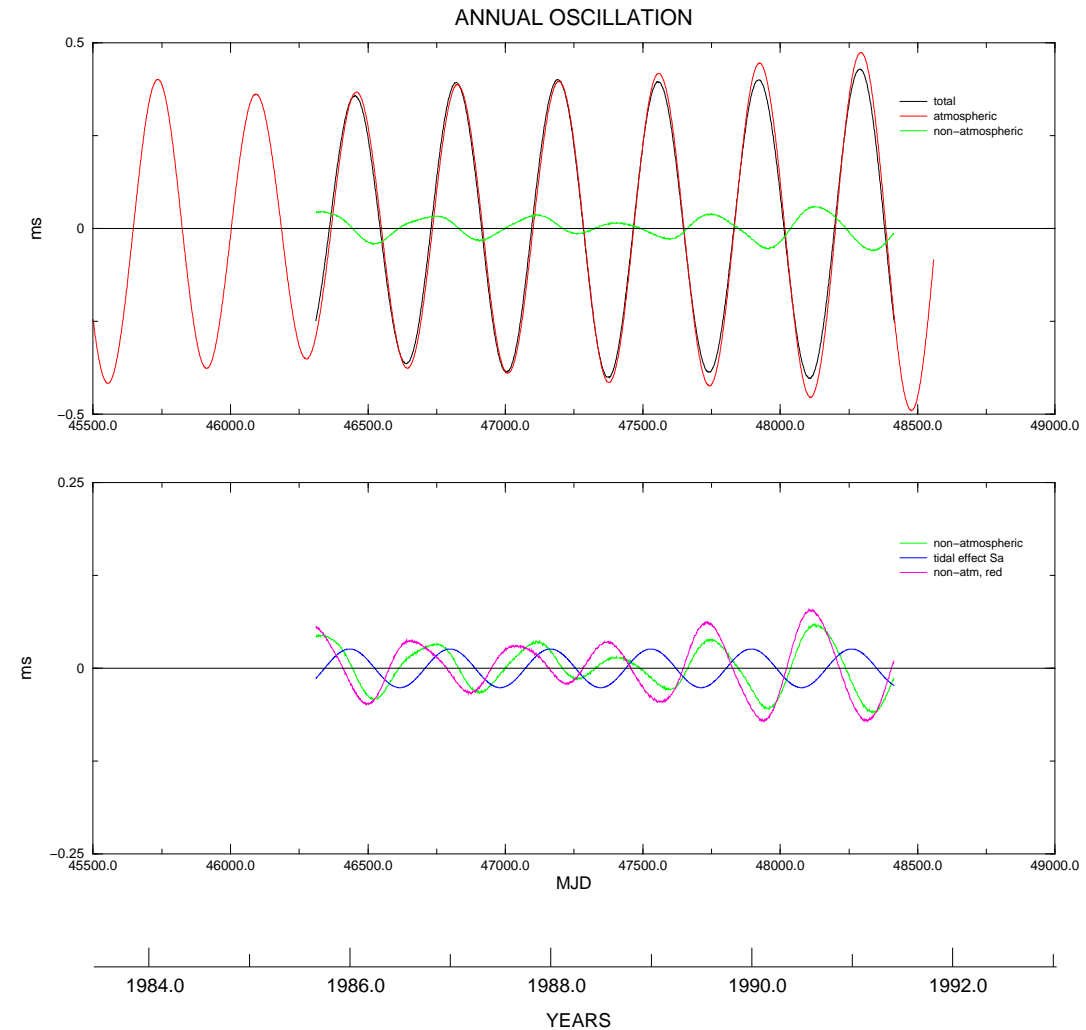

Figure 3. Annual oscillation in the length-of-day variation: Total and atmospheric components as well as non-atmospheric component with and without tidal effect $\mathrm{Sa}$
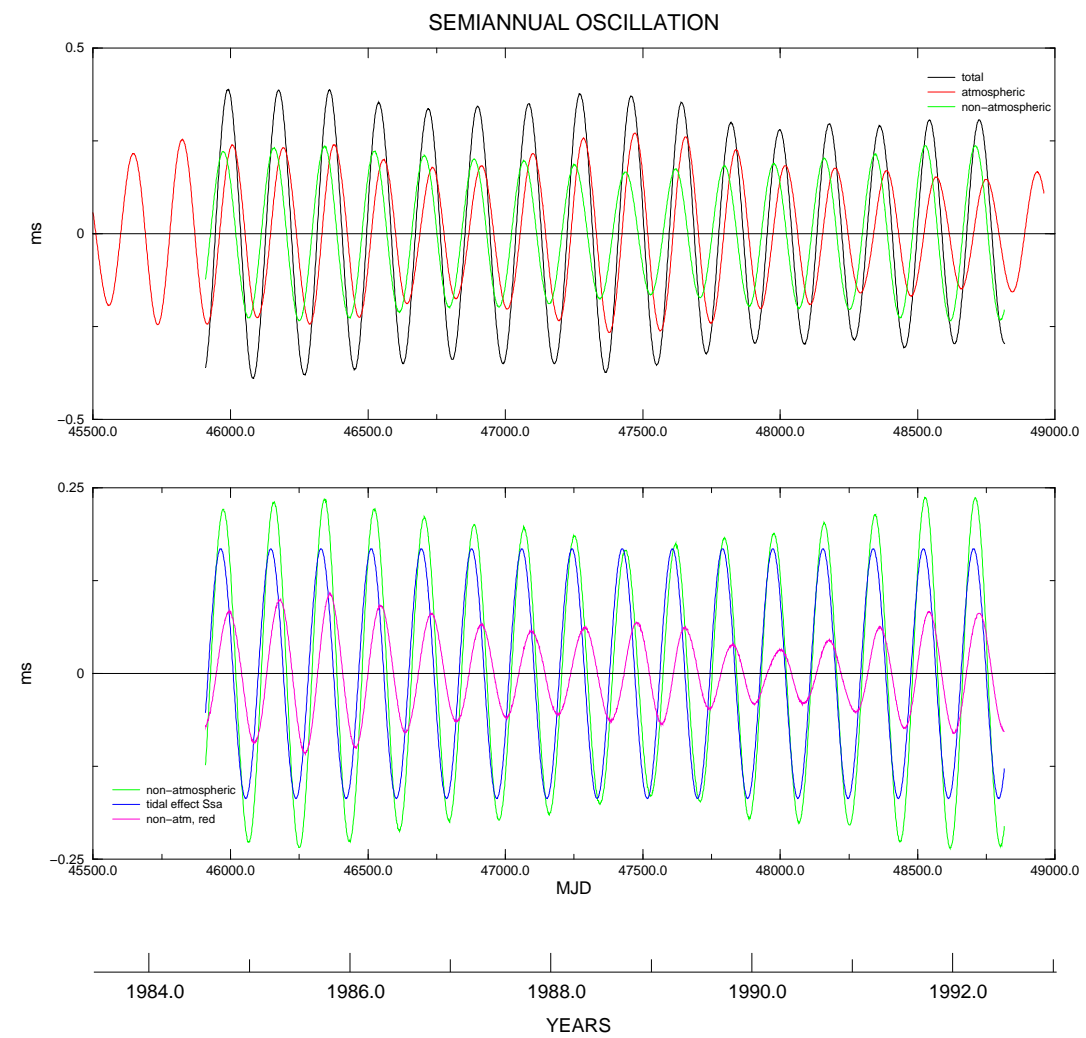

Figure 4. Semiannual oscillation in the length-of-day variation: Total and atmospheric components as well as non-atmospheric component with and without tidal effect Ssa 

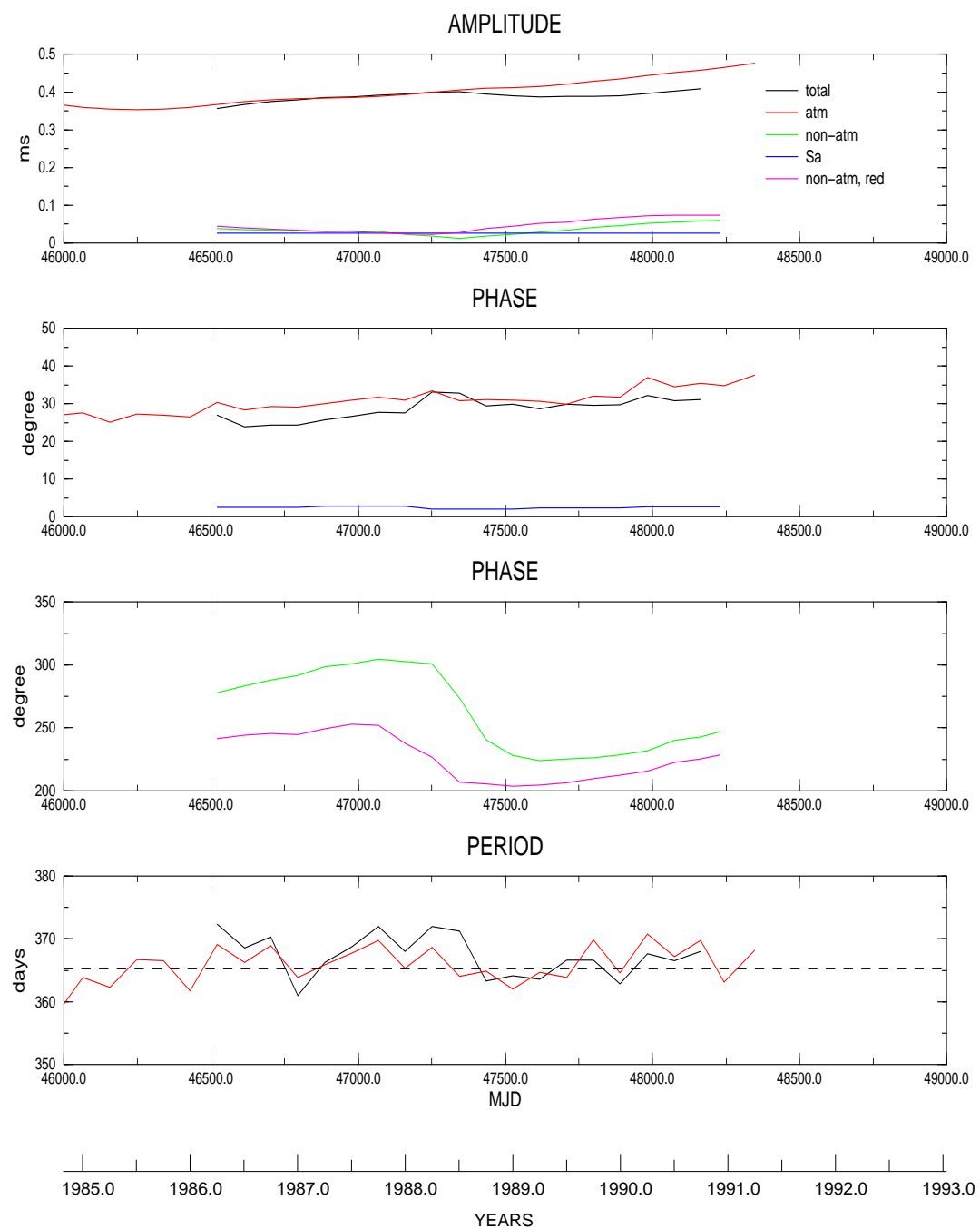

Figure 5. Variability with time of the annual oscillation in the length-of-day variation: Amplitude (top), phase (centre) and period (bottom) estimates of

(a) total oscillation (LOD)

(b) atmospheric component (LOD atm $)$

(c) non-atmospheric component with tidal effect $\mathrm{Sa}\left(\mathrm{LOD}_{\text {non-atm }}\right)$

(d) tidal effect $\mathrm{Sa}$

(e) non-atmospheric component without tidal effect $\mathrm{Sa}\left(\mathrm{LOD}_{\text {non-atm,red }}\right)$

\section{Analysis of seasonal oscillations}

\subsection{Method and results}

As can be seen in Figures 3 and 4, the annual and semiannual oscillations change with time. In order to quantify the temporal changes, amplitudes, phases and periods were computed separately for the different components by a least-squares adjustment with the method of modified harmonic analysis at quarterly intervals, where the period of time chosen for each individual processing is 365 days for the annual oscillation and 183 days for the semiannual oscillation, respectively, plus 29 days at the beginning and at the end of the corresponding period of time moving through the whole time span. The estimated phases refer to cosine functions, where the arguments are expressed with negative phase values. For periodic portions with a very small amplitude, here in particular for the annual non-atmospheric component with and without the tidal effect $\mathrm{Sa}$ as well as the semiannual non-atmospheric component without the tidal effect Ssa, the period should not be included in the adjustment as an unknown.

Figure 5 shows the temporal variation of the total oscillation (LOD), the atmospheric component (LOD atm $)$ and the non-atmospheric components with $\left(\mathrm{LOD}_{\text {non-atm }}\right)$ and without tidal effect $\left(\mathrm{LOD}_{\text {non-atm,red }}\right)$ at annual periods plotted at their median epochs. Regarding the phases, the following should be noted: 
Publication: Scientific Technical Report

No.: STR96/03

Author: J. Höpfner

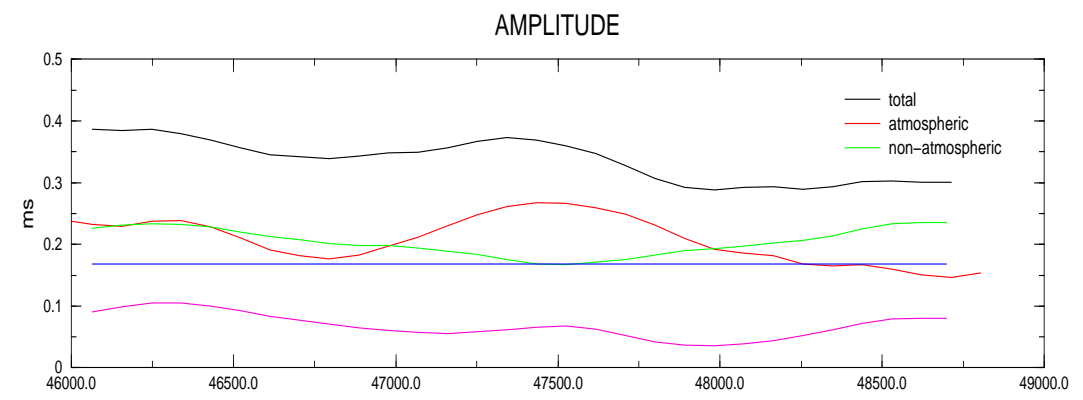

PHASE

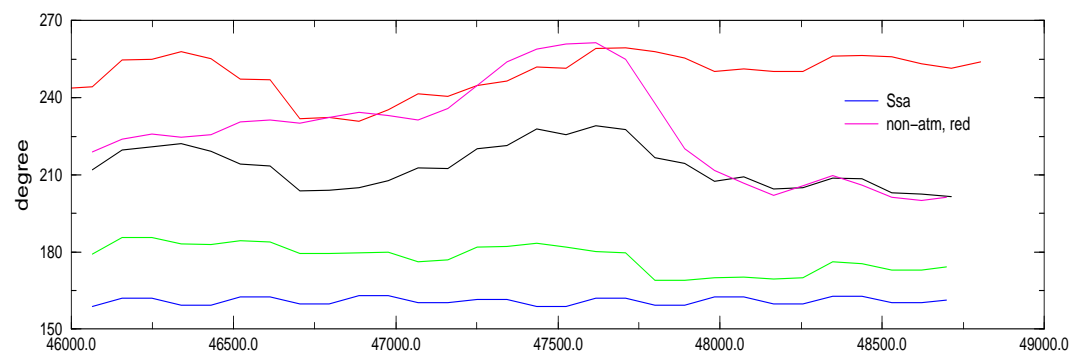

PERIOD

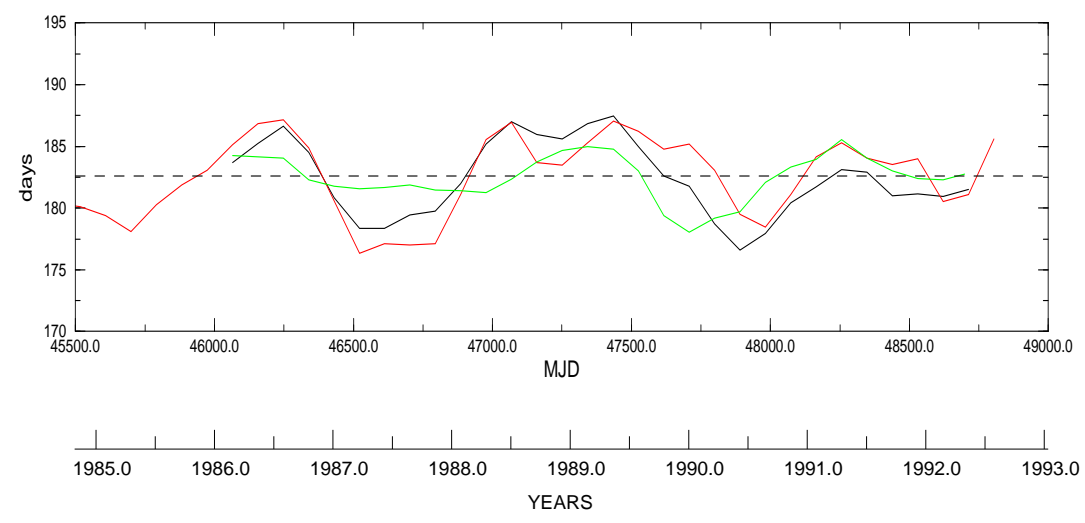

Figure 6. Variability with time of the semiannual oscillation in the length-of-day variation: Amplitude (top), phase (centre) and period (bottom) estimates of

(a) total oscillation (LOD)

(b) atmospheric component $\left(\mathrm{LOD}_{\text {atm }}\right)$

(c) non-atmospheric component with tidal effect Ssa $\left(\mathrm{LOD}_{\text {non-atm }}\right)$

(d) tidal effect Ssa

(e) non-atmospheric component without tidal effect Ssa $\left(\mathrm{LOD}_{\text {non-atm,red }}\right)$ 
Publication: Scientific Technical Report

No.: STR96/03

Author: J. Höpfner

Table 1. Ranges of the variations and of the one-sigma uncertainties of the amplitude, phase and period estimates. Non-atm,red stands for the nonatmospheric component reduced, i. e. corrected for tidal effect. The expression for the oscillations has the form $c \cos (2 \pi t / T-\alpha)$, where $c$ is the amplitude, $\alpha$ the phase and $T$ the period

\begin{tabular}{|c|c|c|c|}
\hline Component & $\begin{array}{c}\text { Amplitude } \\
\sigma_{a m p l i t u d e} \\
{[\mathrm{~ms}]}\end{array}$ & $\begin{array}{c}\text { Phase } \\
\sigma_{\text {phase }} \\
\text { [degree] }\end{array}$ & $\begin{array}{c}\text { Period } \\
\sigma_{\text {period }} \\
\text { [days] } \\
\end{array}$ \\
\hline $\begin{array}{l}\text { (a) Annual oscillat } \\
\text { Total }\end{array}$ & 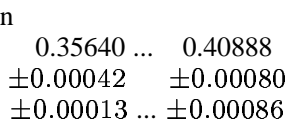 & $\begin{array}{cl}23.93 \ldots & 33.15 \\
\pm 0.32 & \pm 0.05 \\
\pm 0.04 \ldots & \pm 0.32\end{array}$ & $\begin{array}{lll}361.05 & \ldots & 372.37 \\
\pm 0.25 & & \pm 0.19 \\
\pm 0.07 & \ldots & \pm 0.60\end{array}$ \\
\hline Atmospheric & $\begin{array}{ccc}0.35306 \ldots & 0.50406 \\
\pm 0.00030 & \pm 0.00073 \\
\pm 0.00017 \ldots & \pm 0.00093\end{array}$ & $\begin{array}{lll}23.79 & \ldots & 41.89 \\
\pm 0.18 & & \pm 0.12 \\
\pm 0.03 & \ldots & \pm 0.23\end{array}$ & $\begin{array}{lll}353.26 \ldots & 374.35 \\
\pm 0.21 & \pm 0.44 \\
\pm 0.07 \ldots & \pm 0.44\end{array}$ \\
\hline Non-atmospheric & $\begin{array}{ccc}0.01177 \ldots & 0.05927 \\
\pm 0.00076 & \pm 0.00050 \\
\pm 0.00019 \ldots & \pm 0.00076\end{array}$ & $\begin{array}{lll}224.15 \ldots & 304.64 \\
\pm 0.86 & \pm 0.65 \\
\pm 0.26 \ldots & \pm 3.36\end{array}$ & 365.25 \\
\hline $\mathrm{Sa}$ & 0.02600 & 2.74 & 365.25 \\
\hline Non-atm, red & $\begin{array}{ccc}0.02372 \ldots & 0.07437 \\
\pm 0.00048 & \pm 0.00050 \\
\pm 0.00019 \ldots & \pm 0.00071\end{array}$ & $\begin{array}{lll}203.59 & \ldots & 252.85 \\
\pm 0.71 & & \pm 0.43 \\
\pm 0.20 & \ldots & \pm 1.52\end{array}$ & 365.25 \\
\hline $\begin{array}{l}\text { (b) Semiannual os } \\
\text { Total }\end{array}$ & $\begin{array}{l}\text { lation } \\
\qquad \begin{array}{ll}0.28848 \ldots & 0.38638 \\
\pm 0.00052 & \pm 0.00026 \\
\pm 0.00011 \ldots & \pm 0.00123\end{array}\end{array}$ & $\begin{array}{lll}201.51 \ldots & 229.07 \\
\pm 0.07 & \pm 0.21 \\
\pm 0.03 & \ldots & \pm 0.23\end{array}$ & $\begin{array}{ll}176.62 \ldots & 187.46 \\
\pm 0.16 & \pm 0.09 \\
\pm 0.03 \ldots & \pm 0.28\end{array}$ \\
\hline Atmospheric & $\begin{array}{ccc}0.13839 \ldots & 0.26807 \\
\pm 0.00038 & \pm 0.00017 \\
\pm 0.00013 \ldots & \pm 0.00139\end{array}$ & $\begin{array}{lll}230.93 \ldots & 260.10 \\
\pm 0.29 & \pm 0.34 \\
\pm 0.03 \ldots & \pm 0.61\end{array}$ & $\begin{array}{ll}176.35 \ldots & 190.04 \\
\pm 0.23 & \pm 0.51 \\
\pm 0.03 \ldots & \pm 0.51\end{array}$ \\
\hline Non-atmospheric & $\begin{array}{ccc}0.16705 \ldots & 0.23585 \\
\pm 0.00021 & \pm 0.00006 \\
\pm 0.00006 \ldots & \pm 0.00068\end{array}$ & $\begin{array}{lll}169.08 \ldots & 185.70 \\
\pm 0.36 & \pm 0.03 \\
\pm 0.02 \ldots & \pm 0.36\end{array}$ & $\begin{array}{ll}178.05 \ldots & 185.55 \\
\pm 0.12 & \pm 0.16 \\
\pm 0.03 \ldots & \pm 0.30\end{array}$ \\
\hline Ssa & 0.16800 & 160.00 & 182.625 \\
\hline Non-atm, red & $\begin{array}{ccc}0.03585 \ldots & 0.10486 \\
\pm 0.00029 & \pm 0.00027 \\
\pm 0.00010 \ldots & \pm 0.00080\end{array}$ & $\begin{array}{ccc}200.11 \ldots & 261.34 \\
\pm 0.06 & \pm 0.42 \\
\pm 0.06 \ldots & \pm 1.06\end{array}$ & 182.625 \\
\hline
\end{tabular}

(a) If the median epoch lies at the beginning of a year, the zero point of time is fixed at the beginning of this year;

(b) if the median epoch lies at the beginning of the second, third and fourth quarter of a year, the zero point of time is fixed at the beginning of the following year.

Analogous to Figure 5, the temporal variations of the semiannual oscillations are illustrated in Figure 6. Concerning the phases, the following should be noted:

(a) If the median epoch lies at the beginning / in the middle of a year, the zero point of time is fixed at the beginning / in the middle of this year;

(b) if the median epoch lies at the beginning of the second quarter of a year / at the beginning of the fourth quarter of a year, the zero point of time is fixed in the middle of this year / at the beginning of the following year.

In Figures 5 and 6, the reference value selected for the period is 365.25 and 182.625 days, respectively.

Table 1 gives a survey of the range of the variations and of the one-sigma uncertainties of the estimates of the three quantities of the annual and semiannual oscillation components.

\subsection{Discussion of the results}

It should be noted that the estimates of the seasonal oscillation portions reported by Höpfner (1995b) represent average values over the period from 1976 to 1987. As a comparison shows, there is good agreement between those estimates and the time-dependent results of this paper. The present study therefore confirms the general conclusions of the previous one for the oscillation portions in LOD at the seasonal frequencies.

As it can be seen in Figures 5 and 6, the seasonal oscillation components show statistically significant variations of 
their amplitudes, phases and periods with time.

(a) Annual oscillation

The atmospheric component is much larger (up to eight times) than the non-atmospheric component. Both components compose the total oscillation, where the non-atmospheric component has a negative effect which increases with its amplitude. Therefore, the amplitude of the total oscillation is similar or smaller than that of the atmospheric component, where the amplitude difference reaches about $0.1 \mathrm{~ms}$. In Figure 5, note the similar variations in phase and period, respectively, which confirms their reality. It is immediately evident that the period is varying between 355 and 375 days. The tide Sa influences the non-atmospheric component by diminishing its amplitude and retarding its phase. Accordingly, the reduced non-atmospheric component (from which the tidal effect Sa was removed) has a larger amplitude and an earlier phase.

(b) Semiannual oscillation

The atmospheric and non-atmospheric components are of similar amplitude, but there is a phase difference of about $70^{\circ}$. By superposing the two components, a wave with an amplitude being larger by half and a median phase is obtained as the total oscillation. Its variations in phase and period show similar characteristics as those of the atmospheric component, as seen in Figure 6. This similarity confirms that the changes are realistic. Hence, there exists a period variation from 176 to 190 days. The tide Ssa has a positive effect on the non-atmospheric component, i. e., it enlarges the amplitude. In addition to this, the phase is earlier. With respect to the non-atmospheric component without the tidal effect Ssa, it is characterized by smaller amplitude and later phase.

\section{Concluding remark}

The main results of the present investigation are quantitative estimates of the variability of the seasonal length-of-day oscillations arising from atmospheric and non-atmospheric excitations. The annual and semiannual non-atmospheric components without the tidal effects Sa and Ssa, respectively, in LOD indicate additional geophysical excitations besides $\mathrm{LOD}_{\mathrm{atm}}$. At the annual frequency, the solar wind is likely to give a contribution as large as the shortfall (see Gu and Paquet 1993), but there is another possible cause by the effects of the redistributions of air mass and surface water storage (see Chao and O'Connor 1988; Naito and Kikuchi 1990). At the semiannual frequency, the same is to be noted. This means that both portions are not well explained. Hence, it is necessary to look for their sources by further detailed studies.

\section{References}

Chao, B. F. and O'Connor, W. P., 1988. Global surface-water-induced seasonal variations on the Earth's rotation and gravitational field, Geophys. J., 94, 263-270.

Dickey, J. O., 1990. Atmospheric Excitation of the Earth's rotation. In: Boucher, C. and Wilkins, G. A. (Eds.), Earth Rotation and Coordinate Reference Frames. Springer-Verlag, 58-66.

Gu, Z. N. and Paquet, P., 1993. A possible contribution of the solar wind to annual fluctuation in the length of day, Earth, Moon, and Planets, 62, 3, $259-271$.

Höpfner, J., 1995a. Periodische Anteile in der Erdrotation und dem atmosphärischen Drehimpuls und ihre Genauigkeiten, ZfV, $120,1,8-16$.

Höpfner, J., 1995b. Atmosphärische und nicht-atmosphärische Erregung der saisonalen Erdrotationsschwankungen, AVN, $102,2,65-74$.

Höpfner, J., 1995c. Zur saisonalen Erregung der Polbewegung, ZfV, 120, 3, 119-133.

Höpfner, J., 1995d. Saisonale atmosphärische und nicht-atmosphärische Polbewegungsanteile, ZfV, 120, 10, 502-508.

Höpfner, J., 1996. Polar motion at seasonal frequencies, J. Geodynamics, 22, 1/2, 51-61.

IERS, 1996. 1995 IERS Annual Report, Central Bureau of IERS. Observatoire de Paris.

McCarthy, D. D. (ed.), 1992. IERS Conventions (1992), IERS Technical Note 13, Central Bureau of IERS. Observatoire de Paris.

Montag, H., Gendt, G., Dick, G., Reigber, Ch., Nischan, Th. and Sommerfeld, W., 1993. Earth rotation parameters and station coordinates by Lageos laser ranging data updated till mid-September, 1992. IERS Technical Note 14, Central Bureau of IERS. Observatoire de Paris, L23-L29.

Montag, H., Reigber, Ch., Sommerfeld, W. and Dick, G., 1994. Station coordinates and Earth rotation parameters based on Lageos laser ranging data. IERS Technical Note 17, Central Bureau of IERS. Observatoire de Paris, L25-L30.

Naito, I. and Kikuchi, N., 1990. A seasonal budget of the Earth's axial angular momentum. Geophys. Res. Lett., 17, 5, 631-634.

Taubenheim, J., 1969. Statistische Auswertung geophysikalischer und meteorologischer Daten. Akadem. Verl.-Ges. Geest \& Portig. 